\title{
вевенсн Автыст: General profile or general information of the mustard growers (B.F. and NB.F.) according to their selected personal characteristics
}

\section{S. R. Meena and G. S. Bangarva}

Article Chronicle:

Received :

15.03.2019;

Revised :

17.04.2019;

Accepted :

18.05.2019

KEY WoRds :

Impact, KVK's, training, FLD's, DRMR scientists, Knowledge, Adoption, Rapeseedmustard, Oilseeds crops, Mustard growers (B.F. and NB.F.), Recommended mustard production technology

Author for correspondence :

\section{S.R. Meena}

Department of Extension Education, S.K.N. College of Agriculture, Sri Karan Narendra Agriculture University, Jobner-Jaipur (Rajasthan) India

See end of the article for authors' affiliations
SUMMARY : The present investigation was conducted in Bharatpur region of Rajasthan State, India during the years 2014-15, 16-17. Thus present research study has been carried out total 250 mustard growers with the 125 , beneficiary farmers and 125 , non-beneficiary farmers regarding recommended mustard production technology in Bharatpur division. Bharatpur region was purposively selected for the present investigation due to the following reasons: Rajasthan is rank first amongst all the states of India in terms of both area and production of rapeseeds-mustard. Rajasthan state comprises of tenth regions. In Rajasthan, the rapeseeds and mustard crop is most popular oilseeds crops cultivated in this state, its grown on area of 25,32,330 hectares with an annual production of 32,57,987 tonnes and productivity of $1287 \mathrm{~kg} / \mathrm{ha}$. in the years $2015-16$. Rapeseed-mustard is the most important oilseeds crops grown in Rabi season in Bharatpur region of Rajasthan. Bharatpur region occupies first rank in area, production and productivity of rapeseeds and mustard crop amongst the oilseeds crops in tenth regions of Rajasthan. It's mostly grown in five selected districts of Bharatpur division of Rajasthan. This region has covered 7,49,597 hectares of land. Whereas, an annual production of rapeseed and mustard crop is $10,07,502$ tonnes which is very high $1344 \mathrm{~kg} / \mathrm{ha}$. as compared to average national productivity in years 2015-16. DRMR: Directorate of Rapeseed-Mustard Research Station is located in near at Sewar, Bharatpur region of Rajasthan state, in India. Therefore, DRMR, Sewar under Bharatpur region was purposively selected. Front line demonstrations (FLDs) are being laid out regularly by the DRMR scientists on the farmer's field to demonstrate the production potential of rapeseeds-mustard technologies. In this way 25 , beneficiary farmers and 25 , non-beneficiary farmers were selected from the list available at the each KVKs head quarter. Thus, total 50 mustard growers were selected from each KVK by used the simple random sampling technique through proportionate. In this way, all five KVKs of Bharatpur region were selected for the present investigation. From these obtained lists, 125 beneficiary farmers similarly, 125 non-beneficiary farmers were selected. Thus, total sample sizes were consisted of 250 mustard growers from the present research study. Responses were recorded in quantitative form through pre-structured interview schedule technique on the 250 selected mustard growers. The present study was undertaken in Bharatpur region of Rajasthan state, to know the general information/general profile of the mustard growers on a total sample size of 250 respondents. (125, B.F. and 125, NB.F.) regarding recommended mustard production technology. The study highlights that the maximum number, The majority 54 of beneficiary $(43.20 \%)$ and the majority 56 of non-beneficiary $(44.80 \%)$ were having other backward caste. The majority 47 of beneficiary $(37.60 \%)$ and the majorities 49 of non-beneficiary farmers $(39.20 \%)$ were belonged to middle age groups. The majority 21 of beneficiary $(16.80 \%)$ and the majority 44 of non-beneficiary $(35.20 \%)$ were indicate from middle level 


\section{S. R. Meena and G. S. Bangarva}

of education. The majority 42 of beneficiary $(33.60 \%)$ and the majority 12 of non-beneficiary $(9.60 \%)$ were reported from Secondary level of education. The majority 64 of beneficiary (51.20\%) and majority 66 of non-beneficiary (52.80\%) were belonged to medium size of land holding groups. The majority 64 of beneficiary $(51.20 \%)$ and the majority 66 of non-beneficiary $(52.80 \%)$ had from medium level of risk orientation category. The majority 64 of beneficiary $(51.20 \%)$ and the majority 60 of nonbeneficiary $(48.00 \%)$ had from medium level of extension participation category. The majority 35 of beneficiary $(28.00 \%)$ and the majority 32 of non-beneficiary $(25.60 \%)$ had taken FLD on their field. The majority 56 of beneficiary (44.80\%) and the majority 60 of non-beneficiary $(48.00 \%)$ had medium level of economic motivation category. The majority 55 of beneficiary $(44.00 \%)$ and the majority 50 of non-beneficiary $(40.00 \%)$ had medium level of irrigation potentiality.

How to cite this article : Meena, S.R. and Bangarva, G.S. (2019). General profile or general information of the mustard growers (B.F. and NB.F.) according to their selected personal characteristicsAgric. Update, 14(2): 155-169; DOI : 10.15740/HAS/AU/14.2/155-169. Copyright@ 2019: Hind Agri-Horticultural Society. 